\title{
Evaluation of Lactation Management Education Program among Nursing Mothers Attending a Primary Health Care Unit in Suez Governorate, Egypt.
}

\author{
Ahamed E. Shoman ${ }^{1}$, Hanan S. Ez elarab ${ }^{1}$, Sahar k. Kandeel ${ }^{1}$, Heba M.Emam² \\ ${ }^{1}$ Community Environment and Occupational Medicine Department, faculty of Medicine, \\ Ain Shams University, ${ }^{2}$ Family Medicine, Ministry of Health, Egypt.
}

Received: March 2017 Accepted: May 2017

\begin{abstract}
Mothers' poor knowledge and negative attitude towards breastfeeding influence practices and constitute barriers to successful breast feeding. Objectives: To implement a breastfeeding education intervention in a primary health care unit, and to assess the effect of the intervention on knowledge, attitude and practice of nursing mothers. Methods: A health education intervention study was carried out on nursing mothers recruited from attendees of compulsory immunization sessions in one of health care centers of Suez governorate. Sample size estimated to be 250 , selected by systematic random sample. Completing a structured interview questionnaire was done to assess mothers` knowledge and attitude while practice was assessed using a breastfeeding observational checklist. Results: Study was performed on 211 mother-infant pairs. $21.8 \%$ of the mothers were exclusively breast feeding. $82 \%$ of study participants had previous breastfeeding experience. There was a significant improvement in mothers knowledge about advantages of breastfeeding. (mean score: post $13.8 \pm 0.9$ vs pre.9.5 $\pm 2.8 \mathrm{p}<0.001$ ). There was significant improvement of post-intervention mothers' attitude $(\mathrm{p}<0.001)$. A significant improvement in mothers' breastfeeding practice (post $5.6 \pm 0.8$, vs pre-mean \pm SD $3.9 \pm$ $1.71 \mathrm{p}=0.001)$. According to the mothers' wrong believes and barriers to exclusive breastfeeding, the majority $(>80 \%)$ of them reported pain as a major barrier, followed by fear of distorted breast shape, poor prenatal and postpartum support, and insufficient milk production. Conclusion: Breastfeeding intervention was efficient to achieve improvement in mothers' knowledge, attitudes, and practice among attendants of the primary health care unit in Suez governorate.
\end{abstract}

Keywords: Breastfeeding, Knowledge, Attitudes, practices, nursing Mothers, lactation management.

Corresponding author: Heba Mohamed Nigueep Emam E mail: heba.emam @yahoo.com

\section{Introduction}

Protection, promotion, and support of breastfeeding are critical public health needs. ${ }^{1}$ The Lactation Management Education (LME) is the promotion of breastfeeding as a key contributor to optimal infant, maternal nutrition and health. ${ }^{2}$ The WHO recommends that for the first six months of life, infants should be exclusively breastfed to achieve optimal growth, development, and health. ${ }^{3}$ In Egypt, the prevalence of exclusive breastfeeding in first 6 month of life was $39.7 \%$, furthermore, exclusive breastfeeding isn't universal in very early infancy, among infants under two months of age, $71 \%$ was receiving only breast milk. However, the proportion exclusively breastfed drops 
off rapidly among older infants. By age 4-5 months, only around 1 in 8 children were being exclusively breastfed. ${ }^{4}$ Frequently reported problems with breastfeeding include; sore nipples, engorged breasts, mastitis, leaking milk, pain, and failure to latch on by the infant. $^{5}$ Furthermore, there is another reason due to lack of knowledge about the benefit of breastfeeding, and misconceptions like breastfeeding is insufficient, returned to the work. $^{6}$ Difficulties related to mother as HIV infection sever illness of mother, epilepsy, breast abscess, hepatitis $\mathrm{B}^{7}$ Women were struggling with the initiation and continuation of breastfeeding. The main reasons reported for stopping were: perceived insufficiency of milk supply $40 \%$, the baby no longer wanting to nurse $24 \%$, painfulness $15 \%$, time needed to breastfeed $14 \%$ or to pump $7 \%$, need to go back to work $10 \%$ and feeling awkward breastfeeding outside the home $9 \% .^{8}$ Family physicians are in an ideal position to promote and support breastfeeding They are ideal leaders of primary health care systems and partners for public health. ${ }^{9}$

Objectives: (1) To develop and implement a breastfeeding education intervention in a primary health care unit. (2) To assess the effect of health education intervention on improving knowledge, attitude and practice of nursing mothers.

\section{Methods}

This study is a health education intervention study, carried out in ElHaweese primary health care unit in Suez governorate, from October to December, 2015. Study participants were nursing mothers with their infant who attended compulsory vaccination session with their infant. Sampling: systematic random sample was drawn from the compulsory vaccination session list which was taken before-hand to draw the third number in the list, and the follow was taken if the selected one is absent or don't accept to be enrolled in the study. Sample Size: based on the assumption that the baseline rate of mothers with correct knowledge is $50 \%$ and the expected rate after intervention will be $65 \%$. The calculated sample size was 211 with an $\alpha$ error $=0.05$ and $\beta$ error $=0.2$, and $20 \%$ for response rate to be 253 rounded to 250 .

Inclusion criteria: nursing mothers and their Infants aged below6 months, full term babies born between 37 and 42 gestation weeks, and their babies without major birth defects such as congenital heart disease, cleft lip/cleft palate.

Exclusion criteria: Infant of low birth weight Infants with IEM (inborn error metabolism) who did not receive breast milk and any other milk except special formula and the mothers with maternal conditions that may justify permanent or temporary avoidance of breast feeding.

Study tools: An interview semistructured questionnaire to assess knowledge, attitude of mothers - The questionnaire included; 1-Sociodemographic Data (age, education, marital status, income, employment status, maternal history). 2-Mothers Knowledge about Breast Feeding were developed and revised by expertise in nutrition and pediatrics based on the WHO and UNICEF breastfeeding recommendations for optimal infant feeding. ${ }^{10}$ 3-The Iowa Infant Feeding Attitudes Scale (IIFAS) was used to assess mothers' attitudes toward breastfeeding. ${ }^{11}$ 4-Assessment of mother's practice of breastfeeding, include the type, time, pattern and duration of breastfeeding. Assessment of breastfeeding technique through observational breastfeeding check list which covered the most usual 
breastfeeding techniques of postures, positioning, hold practice and latch-on. ${ }^{13}$

Study design: The study was performed on three steps, initial assessment of knowledge, attitude and practice using the interview questionnaire. Educational Intervention was applied. The strategies used for breastfeeding promotion include visual aids, individual counselling (through direct consultation, telephone support, and group educational sessions (either an individualized counseling or group teaching). Each mother in the selected sample was invited to attend at least two to educational breastfeeding sessions, held twice weekly of one hour duration each. The sessions discussed breastfeeding practice issues and mother's enquiries. Given an educational material as colored pamphlet. A post-test was carried out to assess knowledge, attitude and practice using the same pretest questionnaire and practice checklist to test the effectiveness of the intervention.

Ethical consideration: The protocol was approved from the ethical committee of scientific research at the faculty of medicine Ain Shams University. Written informed consent was taken from each subject and assurance of confidentiality and privacy was assured.

Data analysis: Data was revised for completeness and consistency. Data entry and analysis were done with SPSS program (statistical package for social science) for windows version 20.

\section{Results}

This study was done on 211 motherinfant pairs. (55\%) of Mothers were in the age group 25-35ys. income was $(\geq 2000)$ in $69(32.7 \%)$ of the participants. The majority $171(81 \%)$ of them were currently married and were from urban residence $117(55.5 \%)$. almost three fourth of the participants were house wife $149(70.6 \%)$. Nearly half of the participants were institutional educated
(47.9\%) (Table 1). The majority $173(82 \%)$ of the respondents reported to have previous Breastfeeding experience and their Previous BF duration was equal or more than six months $113(65.3 \%)$. and the relatives were the main source of knowledge 126 (59.7\%).

Regarding assessment of mothers' knowledge towards breastfeeding, the total knowledge score significantly increased in post-intervention compered to pre-intervention score $(13.8 \pm .9$ post vs $9.5 \pm 2.79$ pre, $\mathrm{M} \pm \mathrm{SD}, \mathrm{p}<0.001)$, and all for each item (Table 2).

As regards Mothers' attitude towards breastfeeding on IIFA Scale, there is a significant improvement of mother attitude post -intervention compered to pre -intervention in overall $(p<0.001)$ and for each item. Their attitude towards formula feeding (91.9\% post vs $50.3 \%$ pre, $\mathrm{p}<0.001)$, affection of child mother bond $(92.9 \%$ post vs59.7pre, $\mathrm{p}<0.001)$ and "BF improve bonding"( $(82 \%$ post vs $53.6 \%$ pre, $\mathrm{p}<0.001$ ). (Table 4 )

According to the mothers' wrong believes and barriers to exclusive breastfeeding, the majority $(>80 \%)$ of them report pain was a major barrier. Followed by Fear of distorted breast shape, Poor prenatal and postpartum support, and Insufficient milk production (Figure 1).

On examining breastfeeding practices among mothers, at the initial assessment, most of mothers $(67 \%)$ were ever breastfeeding. Exclusive breastfeeding was reported only by $21.8 \%$ of mothers in compered then $73.9 \%$ became breastfeeding only in post intervention $\mathrm{p}<0.001$. The majority of participant were Pacifier user (39.8\% postvs $71.6 \%$ pre, $\mathrm{p}<0.001$ ). Post the intervention there is significant improvement in practice ( $\mathrm{p}$ value < 0.001) (Figure 2).

Assessment of correct breastfeeding technique, initially most of mothers (76.3\%), mother's breast (79.6\%), and 
Table (1): Socio demographic Variables of the participants nursing mothers

\begin{tabular}{|c|c|}
\hline Socio-Demographic $\operatorname{data}(\mathrm{N}=211)$ & $\mathbf{N}(\%)$ \\
\hline $\begin{array}{l}\text { Mother age (years) } \\
18-<25 \\
25-<35 \\
\geq 35\end{array}$ & $\begin{array}{l}60(28.4) \\
116(55.0) \\
35(16.6) \\
\end{array}$ \\
\hline $\begin{array}{l}\text { Current marital status } \\
\text { Married } \\
\text { Divorced } \\
\text { Widow }\end{array}$ & $\begin{array}{l}171(81.0) \\
34(16.1) \\
6(2.8)\end{array}$ \\
\hline $\begin{array}{l}\text { Residence } \\
\text { Rural } \\
\text { Urban }\end{array}$ & $\begin{array}{l}94(44.5) \\
117(55.5)\end{array}$ \\
\hline $\begin{array}{l}\text { Average monthly income } \\
\quad<500 \\
500-<1000 \\
1000-<2000 \\
\geq 2000\end{array}$ & $\begin{array}{l}5(2.4) \\
47(22.3) \\
90(42.7) \\
69(32.7)\end{array}$ \\
\hline $\begin{array}{l}\text { Job } \\
\text { House wife } \\
\text { Working for cash }\end{array}$ & $\begin{array}{l}149(70.6) \\
62(29.4)\end{array}$ \\
\hline $\begin{array}{l}\text { Mother education } \\
\text { Illiterate } \\
\text { Read \& write } \\
\text { Primary } \\
\text { Preparatory } \\
\text { Secondary } \\
\text { University or higher }\end{array}$ & $\begin{array}{l}6(2.8) \\
16(7.6) \\
13(6.2) \\
13(6.2) \\
62(29.4) \\
101(47,9)\end{array}$ \\
\hline
\end{tabular}




\section{Table (2): Assessment of mothers 'knowledge about breastfeeding}

\begin{tabular}{|c|c|c|c|}
\hline \multirow[b]{2}{*}{ Breastfeeding advantages } & \multicolumn{2}{|c|}{$\begin{array}{l}\text { Number of right answers } \\
\mathrm{N}=211 \text { mothers }\end{array}$} & \multirow[t]{2}{*}{ P value } \\
\hline & $\begin{array}{l}\text { Pre- } \\
\text { Intervention } \\
\mathbf{N}(\%)\end{array}$ & $\begin{array}{l}\text { Post- } \\
\text { Intervention } \\
\mathbf{N}(\%)\end{array}$ & \\
\hline $\mathrm{BF}$ is the best & $208(98.6)$ & $209(99.1)$ & 1.000 \\
\hline EBF is the best & $114(54.0)$ & $196(92.9)$ & $<0.001$ \\
\hline BF gives protection (prevent diarrhea, etc.) & $169(80.1)$ & $206(97.6)$ & $<0.001$ \\
\hline protect from obesity & $131(62.1)$ & $209(99.1)$ & $<0.001$ \\
\hline BF babies rarely has constipation & $117(55.5)$ & $207(98.1)$ & $<0.001$ \\
\hline BM is more easily digested & $137(64.9)$ & $210(99.5)$ & $<0.001$ \\
\hline EBF faster milestone development & $120(56.9)$ & $209(99.1)$ & $<0.001$ \\
\hline BF baby will be more intelligent & $115(54.5)$ & $199(94.3)$ & $<0.001$ \\
\hline Improve mother baby bond & $161(76.3)$ & $210(99.5)$ & $<0.001$ \\
\hline BF prevents breast cancer & $155(73.5)$ & $207(98.1)$ & $<0.001$ \\
\hline Prevent osteoporosis in mother & $121(57.3)$ & $203(96.2)$ & $<0.001$ \\
\hline Control postpartum bleeding & $113(53.6)$ & $201(95.3)$ & $<0.001$ \\
\hline BF is cheaper & $152(72.0)$ & $208(98.6)$ & $<0.001$ \\
\hline Save money & $153(72.5)$ & $211(100)$ & $<0.001$ \\
\hline Save time & $128(60.7)$ & $211(100)$ & $<0.001$ \\
\hline Total knowledge score $(15)$ : mean \pm SD & $\begin{array}{l}9.5450 \\
\pm 2.79312\end{array}$ & $\begin{array}{l}13.7820 \\
\pm 0.91018\end{array}$ & $<0.001$ \\
\hline
\end{tabular}

Table (3): Assessment of Breastfeeding practice by Observation: Correct Breastfeeding Technique

\begin{tabular}{|c|c|c|c|}
\hline Assessment Items & $\begin{array}{l}\text { Pre } \\
\text { No }(\%)\end{array}$ & $\begin{array}{l}\text { Post } \\
\text { No }(\%)\end{array}$ & P value* \\
\hline \multicolumn{4}{|l|}{ General look } \\
\hline $\begin{array}{l}\text { - Mother: healthy, relaxed, with baby eye contact } \\
\text { (bonding) }\end{array}$ & $161(76.3)$ & 197(93.4) & $<0.001$ \\
\hline - Baby: healthy, relaxed, reaches or roots for breast & $137(64.9)$ & $189(89.6)$ & $<0.001$ \\
\hline $\begin{array}{l}\text { - Breasts: healthy, no pain, well supported with } \\
\text { fingers }\end{array}$ & $168(79.6)$ & 201(95.3) & $<0.001$ \\
\hline baby's Position a & $124(58.8)$ & $200(94.8)$ & $<0.001$ \\
\hline Baby's Attachment b & $117(55.5)$ & $204(96.7)$ & $<0.001$ \\
\hline Suckling c & $107(50.7)$ & $201(95.3)$ & $<0.001$ \\
\hline Checklist score: mean \pm SD & $3.9 \pm 1.71$ & $5.6 \pm 0.83$ & $<0.001^{* *}$ \\
\hline \multicolumn{4}{|c|}{$\begin{array}{llr}\text { Head and body in line Held } & \text { More areola seen above upper lip } & \text { Slow, deep sucks with pauses } \\
\text { close to mother's body Whole } & \text { Mouth open wide Lower lip turned } & \text { Cheeks round when suckling } \\
\text { body supported Approaches } & \text { outwards. Chin touches breast } & { }^{* *} \text { Wilcoxon Signed Rank test was used } \\
\text { breast; nose to nipple } & & { }^{*} \text { McNemar test was used }\end{array}$} \\
\hline
\end{tabular}


Table (4): Mothers' attitude towards breastfeeding on IIFA Scale

\begin{tabular}{|c|c|c|c|c|c|c|c|}
\hline \multirow[t]{2}{*}{ Attitudes towards breastfeeding } & \multicolumn{3}{|c|}{ Pre-intervention } & \multicolumn{3}{|c|}{ Post-intervention } & \multirow[t]{2}{*}{ P value } \\
\hline & Agree & Neutral & Disagree & Agree & Neutral & Disagree & \\
\hline $\begin{array}{l}\text { The benefits of breast milk last only as long as the baby } \\
\text { is breastfed* }\end{array}$ & $48(12.8)$ & $18(8.5)$ & $145(68.7)$ & $5(2.4)$ & $3(1.4)$ & $203(96.2)$ & $<0.001$ \\
\hline Formula feeding is more convenient $*$ & $58(27.7)$ & $47(22.3)$ & $106(50.3)$ & $14(6.7)$ & $6(2.8)$ & $191(91.9)$ & $<.001$ \\
\hline BF improve bonding & $113(53.6)$ & $50(23.7)$ & $48(22.8)$ & $173(82)$ & $24(11.4)$ & $14(6.6)$ & $<.001$ \\
\hline Formula fed more likely to overfeeding & $111(52.6)$ & $52(24.6)$ & $48(22.8)$ & $163(77.2)$ & $19(9)$ & $29(13.8)$ & $<.001$ \\
\hline Formula feeding is best choice when return to work * & $111(52.6)$ & $54(25.6)$ & $46(21.8)$ & $77(36.4)$ & $29(13.7)$ & $105(49.7)$ & $<.001$ \\
\hline Formula feed miss joys of motherhood & $126(59.7)$ & $40(19)$ & $45(21.3)$ & $196(92.9)$ & $5(2.4)$ & $10(4.7)$ & $<.001$ \\
\hline Not breastfeed in public places* & $104(49.2)$ & $32(15.2)$ & $75(35.6)$ & $71(33.7)$ & $27(12.8)$ & $113(53.5)$ & $<.001$ \\
\hline Breastfed babies are healthier & $109(51.7)$ & $32(15.2)$ & $70(33.2)$ & $194(92)$ & $7(3.3)$ & $10(4.7)$ & $<.001$ \\
\hline BF babies are more likely to overfeeding* & $96(45.5)$ & $46(21.8)$ & $69(32.7)$ & $114(54)$ & $3(1.4)$ & $94(44.5)$ & .064 \\
\hline Husbands feel left out if a mother breastfeeds* & $108(51.2)$ & $41(19.4)$ & $62(29.4)$ & $104(49.3)$ & $10(4.7)$ & $97(46)$ & .002 \\
\hline BM is the ideal food & $122(57.9)$ & $43(20.4)$ & $46(21.8)$ & $203(96.2)$ & $2(0.9)$ & $6(2.8)$ & $<.001$ \\
\hline BM is more easily digested & $112(53.1)$ & $41(19.4)$ & $58(27.4)$ & $192(91)$ & $3(1.4)$ & $16(7.5)$ & $<.001$ \\
\hline Formula is as healthy as breast milk * & $97(46)$ & $41(19.4)$ & $73(34.6)$ & $93(44.1)$ & $9(4.3)$ & $109(51.7)$ & $<.001$ \\
\hline Breast milk is more convenient & $110(52.1)$ & $41(19.4)$ & $60(42.6)$ & $192(91)$ & $5(2.4)$ & $14(6.6)$ & $<.001$ \\
\hline Breast milk is cheaper & $106(50.2)$ & $42(19.9)$ & $63(29.8)$ & $202(95.8)$ & $0(0.0)$ & $9(4.2)$ & $<.001$ \\
\hline $\begin{array}{l}\text { A mother who occasionally drinks shouldn't } \\
\text { breastfeed* }\end{array}$ & $79(37.4)$ & $71(33.6)$ & $61(28.9)$ & $9(4.2)$ & $9(4.3)$ & $193(91.4)$ & $<.001$ \\
\hline BM is lacking in iron* & $194(92)$ & $7(3.3)$ & $10(4.7)$ & $65(30.8)$ & $77(36.5)$ & $69(32.7)$ & $<.001$ \\
\hline
\end{tabular}

Reverse scored

Reverse scored item

Significance $(\mathbf{S}): \mathbf{p}<0,05$

Non Significance (N.S): p>0,05

BM: breast milk 


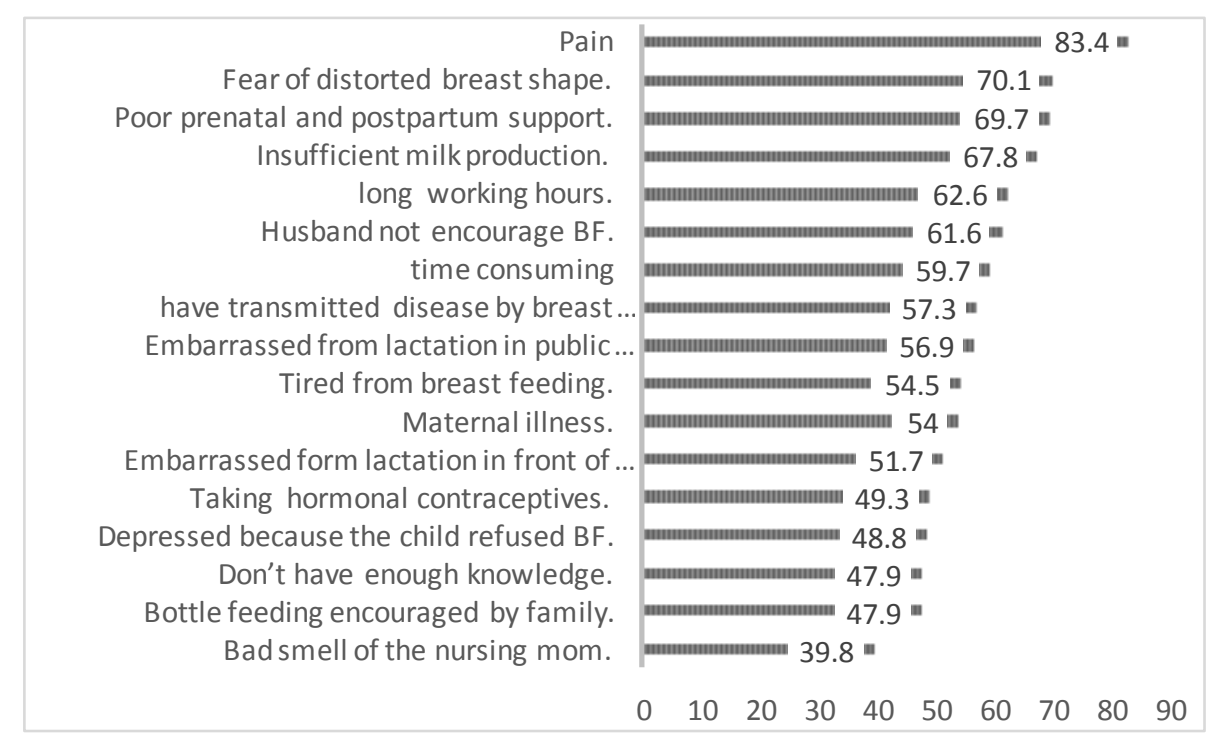

Figure (1): Mothers`wrong believes and barriers toward exclusive breastfeeding.

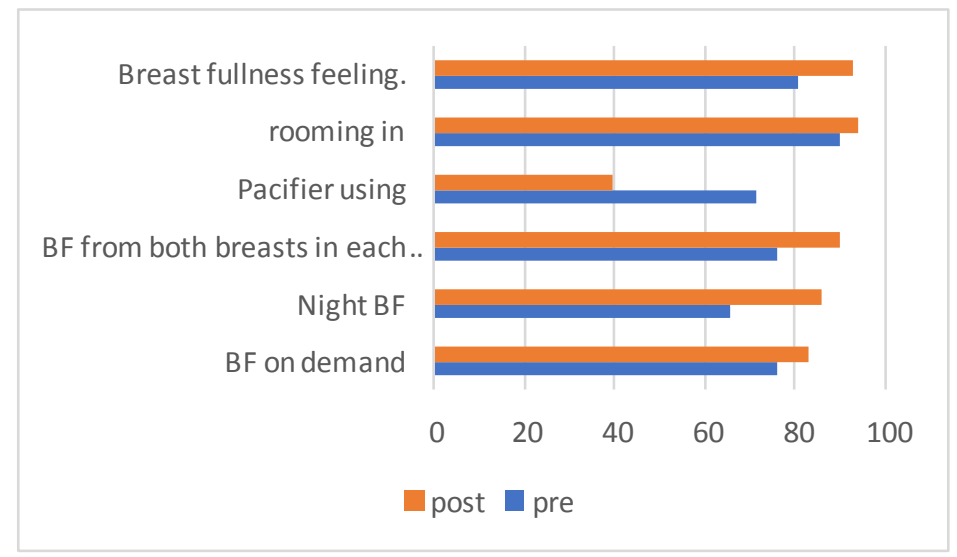

Figure (2) Recall of breastfeeding practices among nursing mothers pre-and postintervention

babies (64.9\%) had good general look. And more than half percent of babies had good body positions (post $94.8 \%$ vs $58.8 \%$ pre, $\mathrm{p}<0.001)$, correct technique of baby's chin touching the breast during breastfeeding and lower lip turned outward was found in $(96.7 \%$ post vs55.5\% pre, $p<0.001)$ and baby's suckling (95.3 post vs50.7\% pre, $\mathrm{p}<0.001)$. After the intervention, there was increasing in mean of total score (mean $\pm \mathrm{SD}=5.6 \pm 0.83$ post vs3.9 \pm $1.71 \mathrm{pre}, \mathrm{p}=0.001)$ (Table- 3$)$.

\section{Discussion}

Breastfeeding contributes not only to achieving many of the SDGs, it is also a critical component of the Global Strategy for Women's, Children's and Adolescents' Health. ${ }^{12}$ In this study, less than quarter of the mothers were exclusively BF with in the first 6 months of their infants age $(21.8 \%)$ in preintervention phase. The overall mother's knowledge was $(9.5 \pm 2.8)$ of total score fifteen. This result was nearly similar to that found in previous studies in Egypt, India, Nepal and Bangladesh (13-15). Most of mothers in this study $98.6 \%$ knew that breastfeeding is the best 
nutritional source for baby. Breast milk promoted bonding between mothers their child $(76.3 \%)$ and protects child from diseases $(80.1 \%)$. After the health education intervention, there was a significant improvement in mothers` knowledge towards BF $(\mathrm{p}<0.001)$. Nearly half of mothers only agree with the beneficial of BF on child (developmental milestone) (54.5\%) and mother health -protecting osteoporosis (57. 3\%). The majority (94.8) of participants in current study didn't receive any breastfeeding education before. And this may be the cause of their lower knowledge scores. and raise the need for breastfeeding health education provided at PHC centers.

In the current study, the sources of mothers' information regarding breastfeeding, the main source was from family members $(59.7 \%)$. It was even higher $(96.0 \%)$ in Sinai governorateEgypt $^{14}$ and Iranians mothers $(54 \%) .{ }^{19}$ These results are also in Benghazi, Libya where the majority of respondents reported having information from their mother- in-law, a relative, or a neighbor. ${ }^{20}$ Health care providers in this study were the second source of information $(34.6 \%)$. On the other hand, a study involving women in Lebanon showed that the vast majority of mothers reported that physicians were the most influential in their knowledge about the breastfeeding $(42.8 \%)^{21}$

Positive maternal attitudes towards infant feeding are reported to be an important component in child nutritional health. ${ }^{22}$ In the Middle Eastern countries, which is mainly In the Islamic culture very supportive to BF. The Qur'an therefore promotes breastfeeding: 'Mothers shall give suck to their children for two full years for those who desire to complete the term'. Qur'an, 2:233 We carried the present study among middle social class, majority were Muslims. Using IIFAS for measuring attitude, the result revealed that, mothers had neutral attitude $(53.5 \pm 4.9)$ similar to other study results in Egypt and different parts of the world ${ }^{14,23,24}$ and they wrongly believe that formula is as healthy for infants as breast milk $46 \%$. These results are consistent with Abdulsalam (43.9\%), DarbyCarlberg (36\%) ${ }^{(25) .}$ Further, around Fifty percent of the included mothers agreed or strongly agreed that formula- feeding is the better choice for a working mother. And there was weak response 24\% lacking husband support and even after the intervention which indicate room for future improvement through involve husband in the training process. $27.7 \%$ of nursing mothers in this study had a positive attitude towards formula feeding "Formula feeding is more convenient", this could be due to lack of their knowledge about the advantages of breastfeeding. After the intervention, there is significant improvement of mother attitude $(p<0.001)$. Their attitude towards formula feeding become more negative $(91.9 \%$ post vs $50.3 \%$ pre, $\mathrm{p}<0.001$ ), affection of child mother bond $(92.9 \%$ post vs 59.7 pre, $\mathrm{p}<0.001)$.

Mother's believes regarding possible barriers toward exclusive breastfeeding, $(83.4 \%)$ of mothers perceived that exclusive breastfeeding Inducing breast pain to mother and insufficient breast milk production $(67.8 \%)$. unsuitable for working mothers $62.6 \%$, distorted breasts shape $70 \%$ and it needs more effort and time $60 \%$, embarrassed from lactation in public place $56 \%$. Others assessed barriers to EBF as, A. Latifa et al. ${ }^{26}$, who reported 28\% and 15\% from Saudi and Egyptian mothers' dissatisfaction with EBF. Their misconceptions included, inadequate breastmilk, and that BM is not applicable outdoor, neither suitable for working or busy mothers, and not proper for mothers with breast problems, in addition it needs more time and effort. This finding agree with by McCann et al. ${ }^{31}$ who reported concerns among WIC 
participants in US about insufficient milk supply, painful breasts during feeding, sexuality issues, maternal smoking, contraception, negative self-image, and embarrassment from public breastfeeding as reasons for early cessation. Other Published reports as well indicate that, insufficient milk supply was the most common reason cited by the women for weaning. ${ }^{32,31}$

Breastfeeding is one of the oldest practices, recommended in Holy Quran, Biblical records and the ancient Hindu scriptures. ${ }^{34}$ Current study EBF is lower than EDHS 2014 report $39.7 \%^{4}$, and in an Egyptian survey $39.9 \%,{ }^{14}$ and in previous international studies in Jordan $36 \%{ }^{30}$ in Emirate $25 \%,{ }^{31}$ in Ethiopia $55.6 \%{ }^{(32) .}$ On the other hand, this result is better than what has been reported by previous studies conducted in Egypt in a rural area whereas only 9.7\% (103 of $1,059)$ were exclusively breastfeeding their infants ${ }^{33}$ in Kuwait $10.5 \%,{ }^{34}$ in India $(7.8 \%$ and $16.5 \%){ }^{(35,36) .}$

In our study, $76.3 \%$ of the mothers fed their infants on demand. This finding agree with Abul-Fadl ${ }^{37}$ which reported feeding on demands of $78.9 \%$ in Lower Egypt and $76.3 \%$ in Upper Egypt. Rooming-in was practiced by $90.0 \%$ of mothers, which is much higher than that reported in Egypt about (65\%) mothers were practicing night feeds, while $23 \%$ of mothers practiced feeding one side at a time. $^{38}$

Unfortunately, in current study, mothers use of Pacifier for their babies was $71.6 \%$, This is higher than an Egyptian study which found that $43.2 \%$ of women from lower Egypt and 39.4\% from upper Egypt have given their children pacifiers. ${ }^{37}$ Also, supported with different studies which reported that the use of pacifiers is deeply rooted in Egyptian culture. The association between pacifier use and shorter duration of breastfeeding and exclusive breastfeeding is proved. Children using pacifiers were 1.9 times more likely to have stopped breastfeeding by the 6th month compared to non-users. ${ }^{39}$ Post the intervention there is a change of this ad practice ( $\mathrm{p}$ value < 0.001 ).

Pre-and post intervention practice, assessed score were, only $55 \%$ of the mothers were practicing correct breastfeeding attachment and positioning technique.

Nearly all women can breastfeed if they are supported to be confident and aware of good techniques and promotion of practices avoid the early introduction of complementary foods for sociocultural reasons. ${ }^{40}$ A study conducted in Uganda found that health education to support BF was both feasible, accepted and inexpensive intervention. ${ }^{41}$

Our study showed that education and motivation to breastfeeding was a predictor of change in knowledge, attitude and practice.

\section{Limitations}

The present study has certain limitations such as intervention in nature. Small sample size that made difficult to generalize the findings. Further largescale community surveys are recommended in this area for drawing conclusions. Mothers more likely to be involved/ consent would be living near the center, and have a higher education level.

\section{Conclusions}

Breastfeeding promotion interventions improved mothers' knowledge and attitudes toward breast feeding. And the level of practice significant increased among nursing mothers.

\section{Recommendations}

It is important to provide accurate prenatal and post education that focuses on methods and long-term benefits of infant feeding to mothers, family and health professionals. 


\section{Acknowledgements}

We are very much grateful to all participants of study for their kind cooperation.

\section{References}

1. United States Department of Health and Human Services (2014): Healthy People 2020, Maternal, Infant, and Child Health. 2014 July 16, 2014]; Available from (www.healthypeople.gov).

2. Audrey J, Ruth A. (2014): Lactation Management Self-Study. Modules, Level I. This Edition of Wellstart International's Lactation Management Self-study (www .wellstart.org/Self-Study-Module.pdf)

3. World Health Organization (2016): Infant and young child feeding. Fact sheet. www.who.int/mediacentre/factsheets/fs3 42/en/ . Updated September 2016.

4. Egypt Demographic and Health Survey (2014): practices for infant and young child feeding, pdf.usaid.gov/ pdf_ docs/ pbaab 419.pdf.

5. Cupul-Uicab LA, gladen BC, Hernndez-Avila M, Longnecke MP (2009): Reliability of reported breastfeeding duration among reproductive-aged women from Mexico, Matern Child Nutr; 5:125-37.

6. Kristiansen, Maria V.; Diaz, Vanessa A.; Mainous Ag, Arch G.; Geesey, Mark E (2010). "Prevalence of Breastfeeding and Acculturation in Hispanics. Birth 32 (2): 93-8.

7. WHO (2007): World Health Organization. Global strategy for infant and young child feeding. WHO; Geneva: 2007.

8. Neifert M, Bunik M (3013): overcoming barriers to breastfeeding continuation and exclusivity; Pediatric Clinics of North America; 22(5):655-63.

9. American Academy of Pediatrics (2010): Section on Breastfeeding: Probiotics and prebiotics in pediatrics; Pediatric; 103:178-187.
10. World Health Organization (2009): Global data bank on infant and young child feeding.2009. http://www.who.int/ nutrition/ databases/ infantfeeding/ countries.

11. Sittlington J, Wright M, Bradbury I, Scott JA (2006): Infant-feeding attitudes of expectant mothers in Northern Ireland. Health Educ Res 22(4):561-570.

12. UNICEF (2016): Breastfeeding and the Sustainable Development Goals, Factsheet.

13. WHO (2006): Infant and young child feeding counselling: an integrated course. WHO Library Cataloguing-inPublication Data, www.who.int/nutrition/publications/IYC F_Participants_Manual.pdf

14. Abdulsalam Mohammed and Yassein Ahmed (2016): Breastfeeding Knowledge, Attitude, and Practices among Mothers Attending H C in Sana'a City; ARC Journal of Public Health and Community Medicine 1(2): 9-17.

15. Afrose L, Banu B, Ahmed K.R. and Khanom K (2012): Factors associated with knowledge about breastfeeding among female garment workers in Dhaka city," WHO SouthEast Asia Journal of Public Health. 1(3): 249-255.

16. Mohamed SA, Mohamed AG, Mohamed EM, Khalek EM (2012): Knowledge and practices of working mother about breastfeeding and weaning in Assiut city, Egypt. Life Sci J; 9: 803-8.

17. Khamnian Z, Azarfar A and Hasanpour K (2013):"Exclusive Breastfeeding and Factors Affecting Knowledge, Attitude and Practice of Mothers in Rural and Urban Regions of East Azerbaijan, Iran," Life Science Journal 10(5s): 473-478.

18. Ekanem IA, Ekanem AP, Asuquo A, Eyo VO (2012): Attitude of working mothers to exclusive breastfeeding in Calabar municipality, cross river State, Nigeria. Journal of Food Research; 1:7175. 
19. Madanat H, Farrell H, Merrill R and Cox E (2007): Breastfeeding Education, Support, and Barriers among Iraqi Refugee Women in Jordan," International Electronic Journal of Health Education. 10: 138-149.

20. Balo NNM and Singh R (1996): Maternal Characteristics and infant and young child feeding in Benghazi. East Mediterranean Health Journal; 2(3): 432439.

21. Batal M, Boulghourjian $\mathrm{C}$, Abdallah A, Afifi R (2006): Breastfeeding and feeding practices of infants in a developing country: a national survey in Lebanon. Public Health Nutrition; 9(3):313-319.

22. Wojcicki JM, Kathiravan S, Holbrook K, Heyman MB (2010): Early exclusive breastfeeding and maternal attitudes towards infant feeding in a population of new mothers in San Francisco, California. Breastfeed Med; 6(1): 9-15.

23. Inoue $\mathrm{M}$, Binns $\mathrm{CW}$, Katsuki $\mathrm{Y}$ and Ouchi M (2013): Japanese mothers' breastfeeding knowledge and attitudes assessed by the Iowa Infant Feeding Attitudes Scale, Asia Pac J Clin Nutr. 22(2): 261-265.

24. Chen S, Binns CW, Liu Y, Maycock B, Zhao Y and Tang L (2013): Attitudes towards breastfeeding - the Iowa Infant Feeding Attitude Scale in Chinese mothers living in China and Australia, Asia Pac J Clin Nutr. 22(2): 266-269.

25. Darby-Carlberg CL (2010): Attitudes of young adults about breastfeeding and the association of breastfeeding exposure. UNLV Theses. 195 (2010).

26. Latifa A, Hoda M (2016): Exclusive Breastfeeding, Prevalence and Maternal Concerns: Saudi and Egyptian mothers. Journal of Education and Practice www.iiste.org ISSN 2222-1735 (Paper)ISSN 2222-288X (Online) Vol.7, No.3.
27. McCann ME, Baydar N \& Williams RL (2007): Breastfeeding attitudes and reported problems. in a national sample of WIC participants. Journal of Human Lactation, 23(4): 314-324.

28. Chen CH, Chi CS (2003): Maternal intention and actual behavior in infant feeding at one month postpartum. Acta Paediatr Taiwan; 44:140-4.

29. Shembesh NM, Balo NN, Singh R (1997): Breast-feeding and weaning patterns in Benghazi, Libyan Arab Jamahiriya. East Mediterr Health J; 3:251-7.

30. Sunna LF (2012): Child Feeding Patterns and Diarrhea, Mu'tah University, Al-Karak Governorate, Jordan, 2012.

31. Radwan H (2013): Patterns and determinants of breastfeeding and complementary feeding practices of Emirati Mothers in the United Arab Emirates, BioMed Central, Public Health, 13(171): 1-11.

32. Tamiru D and Mohammed S (2013): Maternal knowledge of optimal breastfeeding practices and associated factors in rural communities of Arba Minch Zuria, International Journal of Nutrition and Food Sciences, 2(3): 122129.

33. Al Ghwass MM, Ahmed D (2011): Prevalence and predictors of 6month exclusive breastfeeding in a rural area in Egypt; 6(4):191-6.

34. Dashti $M$ and Al-Sughayer $M$ (2010): "Determinants of breastfeeding initiation among mothers in Kuwait," I B F Journal, vol. 5, no. 7, pp. 1-9, 2010.

35. Tiwari R, Lahariya C (2009): The determinants of exclusive breastfeeding in urban slums: a community based study. J Trop Pediatr; 55: 49-54.

36. Bandyopadhyay M (2009: Impact of ritual pollution on lactation and breastfeeding practices in rural West Bengal, India. Int Breastfeed J; 4: 2. 
37. Abul-Fadl A.M. El-Taweel A, and Turner-Maffei C (2012): Evaluation of Mothers' Knowledge, Attitudes, and Practice towards the Ten Steps to Successful Breastfeeding in Egypt. Breastfeeding Medicine; 7 (3): 173-178.

38. World breastfeeding trends initiative indicators (2011): International Baby Food Action Network (2011) http://www.world breastfeeding trends. Org.

39. Soares ME, Giugliani ER, Braun ML, Salgado AC, de Oliveira AP, de Aguiar P (2005): Pacifier use and its relationship with early weaning ]. Indian $\mathrm{J}$, Pediatric. Breastfeeding and pacifier use in Brazil; 72(3):209-12.
40. Kronborg H, Vaeth M (2009): How are effective breastfeeding technique and pacifier use related to breastfeeding problems? Birth; 36:34-42. 41. Sinclair S and Snell-Ings (2003): Breastfeeding practices in northern ontario. child health survey. www. Pediatrics Digest Mobicom Assessed 14/9/2012, 2003.

42. Nankunda J, Semi-Yaga N and Ndeezi G (2006): Community based peer counsellors for support of exclusive breastfeeding: Experiences from Rural Uganda, (1): 19 
